\title{
HOW A GEOLOGY ALUMNI SOCIETY AND PROFESSIONAL COMMUNITY CONTRIBUTE TO THE PREPARATION OF GRADUATE STUDENTS FOR A GEOSCIENCE CAREER AT THE UNIVERSITY OF SOUTH FLORIDA
}

Bruce Nocita, Charles Connor, Gregory Herbert, Mark Rains, Eileen Rodriguez, Jeffrey Ryan, and H. Len Vacher. 
The Geology Alumni Society (with the unfortunate acronym of GAS) at the University of South Florida was established in 1997.

At that time it was envisioned as a social group to keep alumni connected but quickly became involved in fundraising. 


\section{Around this time Richard (Skip) Davis started an endowment fund for graduate students.}

This quickly became the first directed collaboration of the Society, the department and students. 
There are four areas of activity where the GAS, professional community and Department interact:

1. Workshops/Expos

2. Networking and Fundraising

3. Curricula Development

4. Professional Science Masters 


\section{WORKSHOPS/EXPOS}

- Annual resume writing workshop

- PG workshop

- Career in Geoscience workshop - led directly to the development of an undergraduate class

- Bi-annual Expo - variety of companies set up booths and exhibits in the nearby Geo-Park. 
University of South Florida Geology Alumni Society Presents

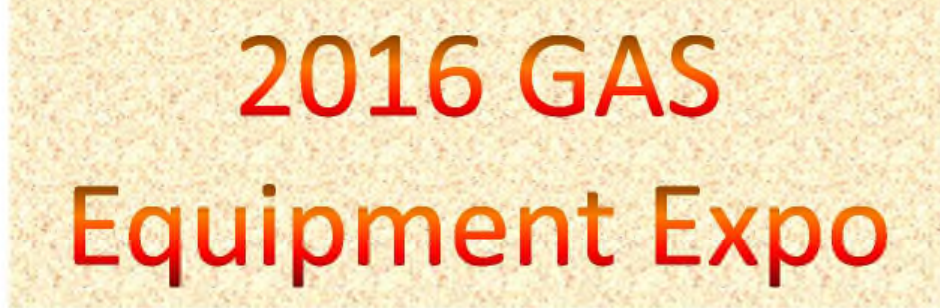

Demonstrations/Exhibits to Include:

-Groundwater Sampling Technologies

When: April 27, 2016

-Drilling Demonstrations

-Geophysical Instrumentation

- Florida Geological Exhibits

-Representatives from Local and State

Professional and Governmental

Agencies

-The Hydro-Volcano and Florida Cave

-Environmental Assessment and

Remediation Technologies

from $1 \mathrm{pm}$ to $4 \mathrm{pm}$

Where: USF GeoPark

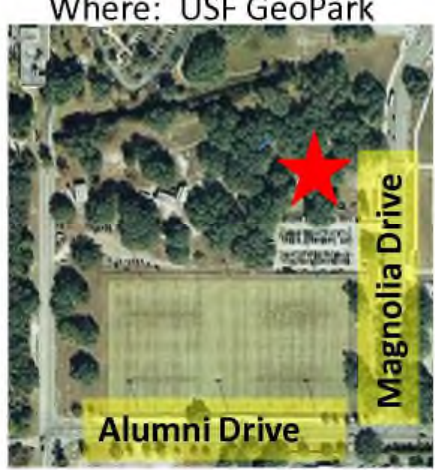

An Event for The School of Geosciences (Geology, Geography and ESP)

-Equipment Demonstrations From the -Student Research Poster

Geological, Environmental and Competition with Cash Awards

GeoTechnical Professions $\quad$ Hydro-Volcano Demonstration

-Professionals from Local Private

Industry and Governmental Agencies

-Student Resume Boards

-SWFWMD Rock Cores and Well

Lemonstration

- Job Opportunity Postings

-The Spring Rock Breaker will follow

-Networking Opportunity

Brady's

For more information contact Mike Wightman: 813-690-6667 or mwightman@geoviewinc.com 


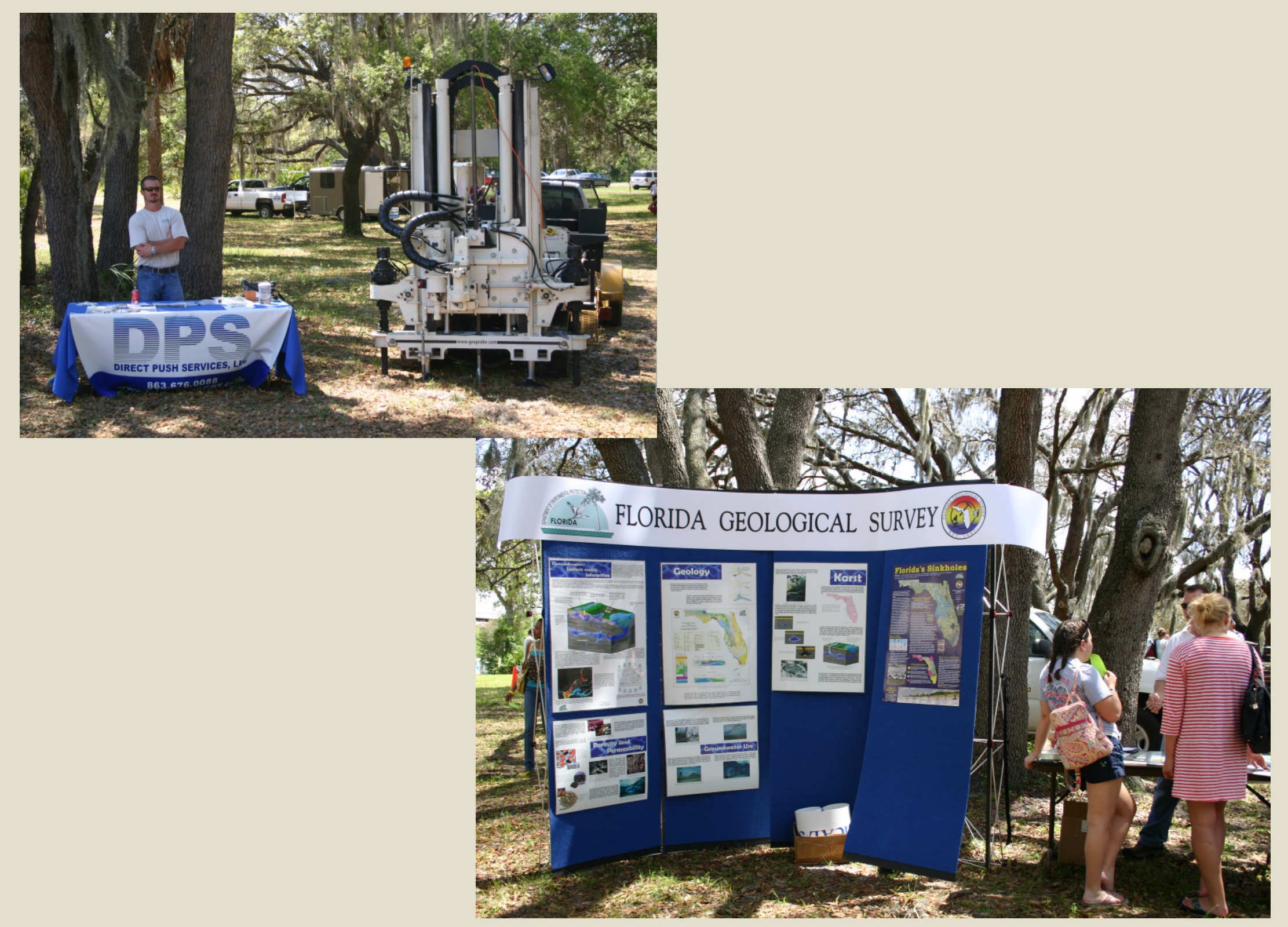

AS\&ME

USF UNIVERSITY OF 


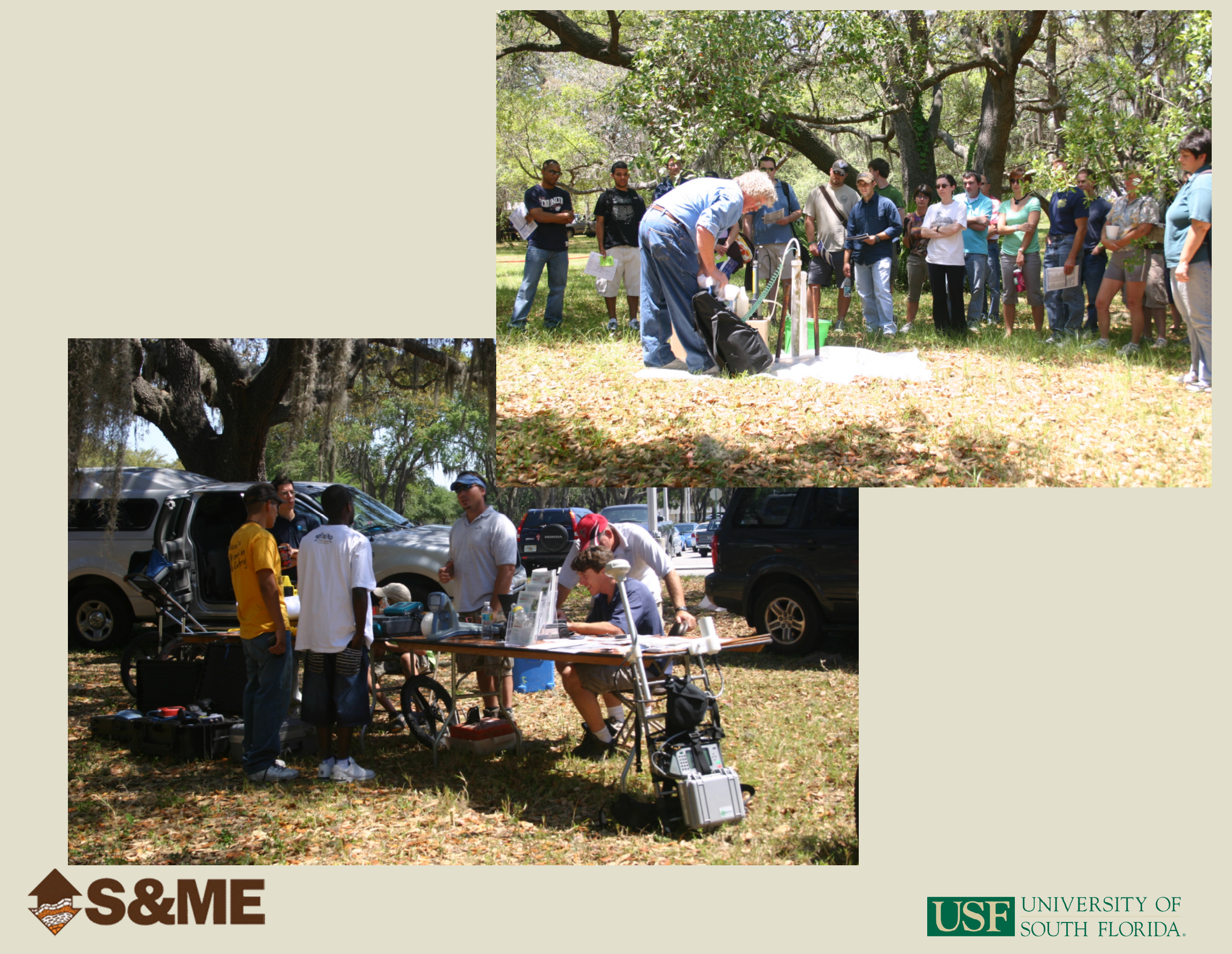




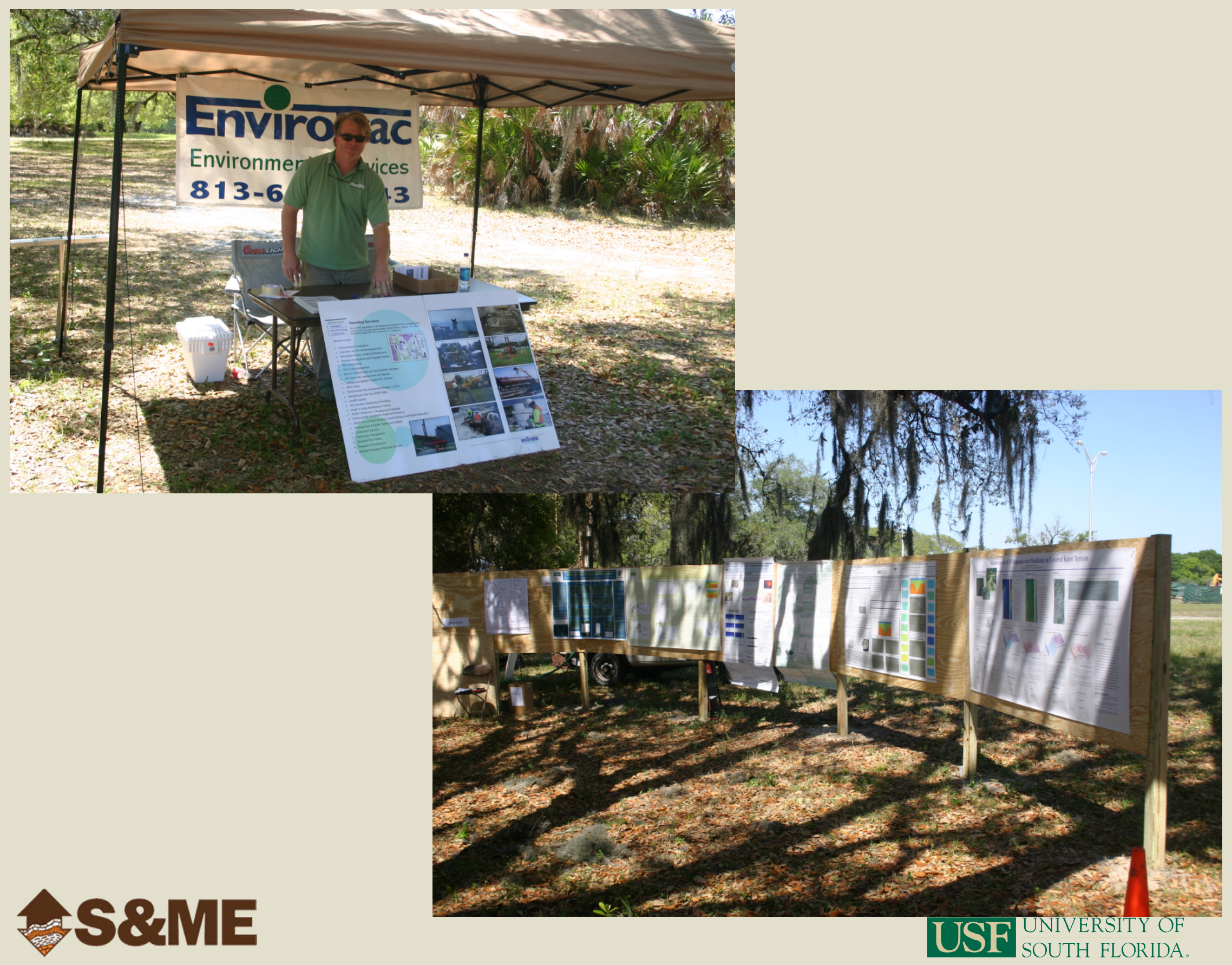




\section{NETWORKING/FUNDRAISING}

- Annual Banquet - Fundraising, networking, student outreach

- MS and PhD scholarships

- Social events (Rockbreaker) - kick off the new semester

- Field School Endowment and Scholarship funds 


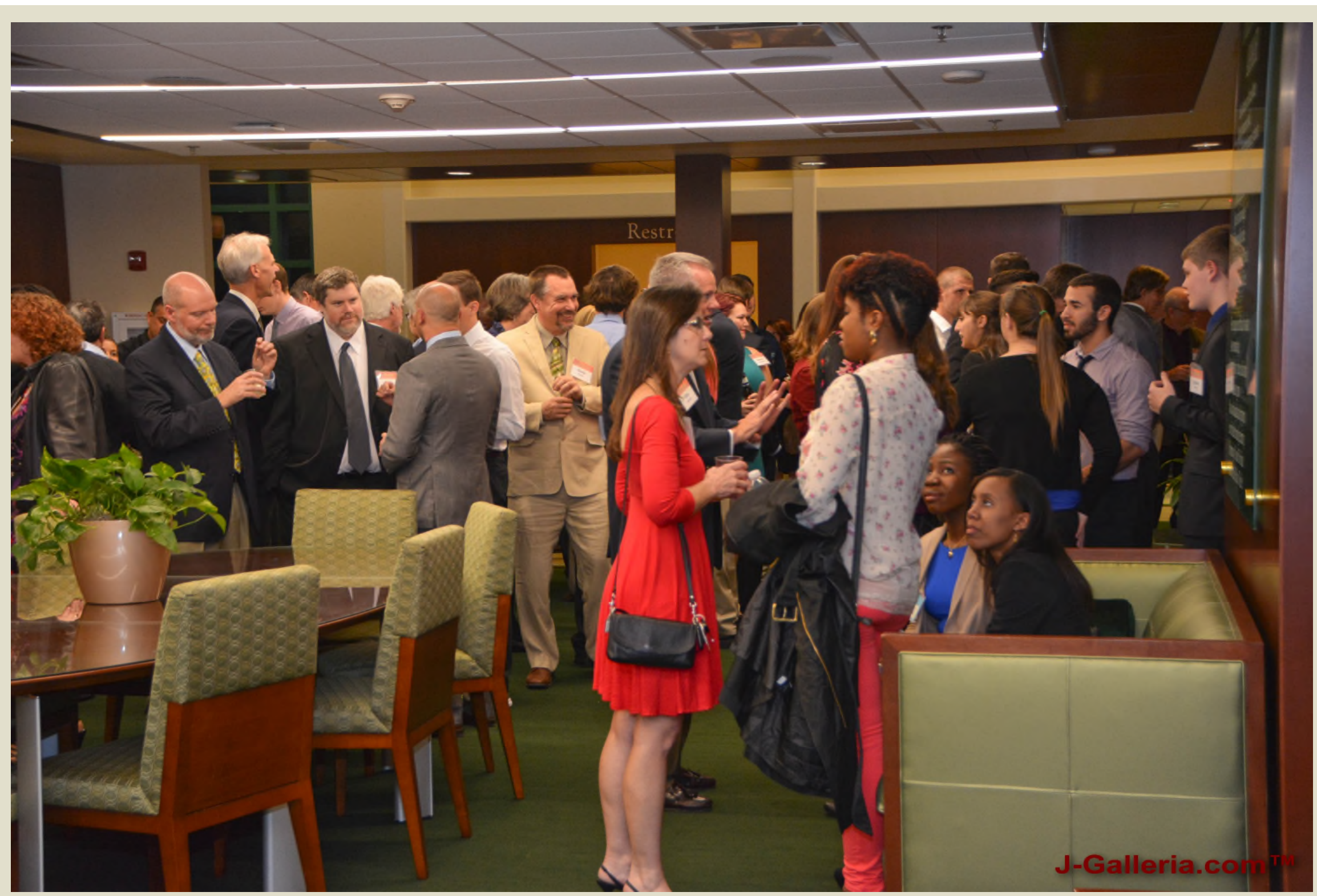

A-S\&ME

USF $\begin{aligned} & \text { UNIVERSITY OF } \\ & \text { SOUTH FLORIDA. }\end{aligned}$ 


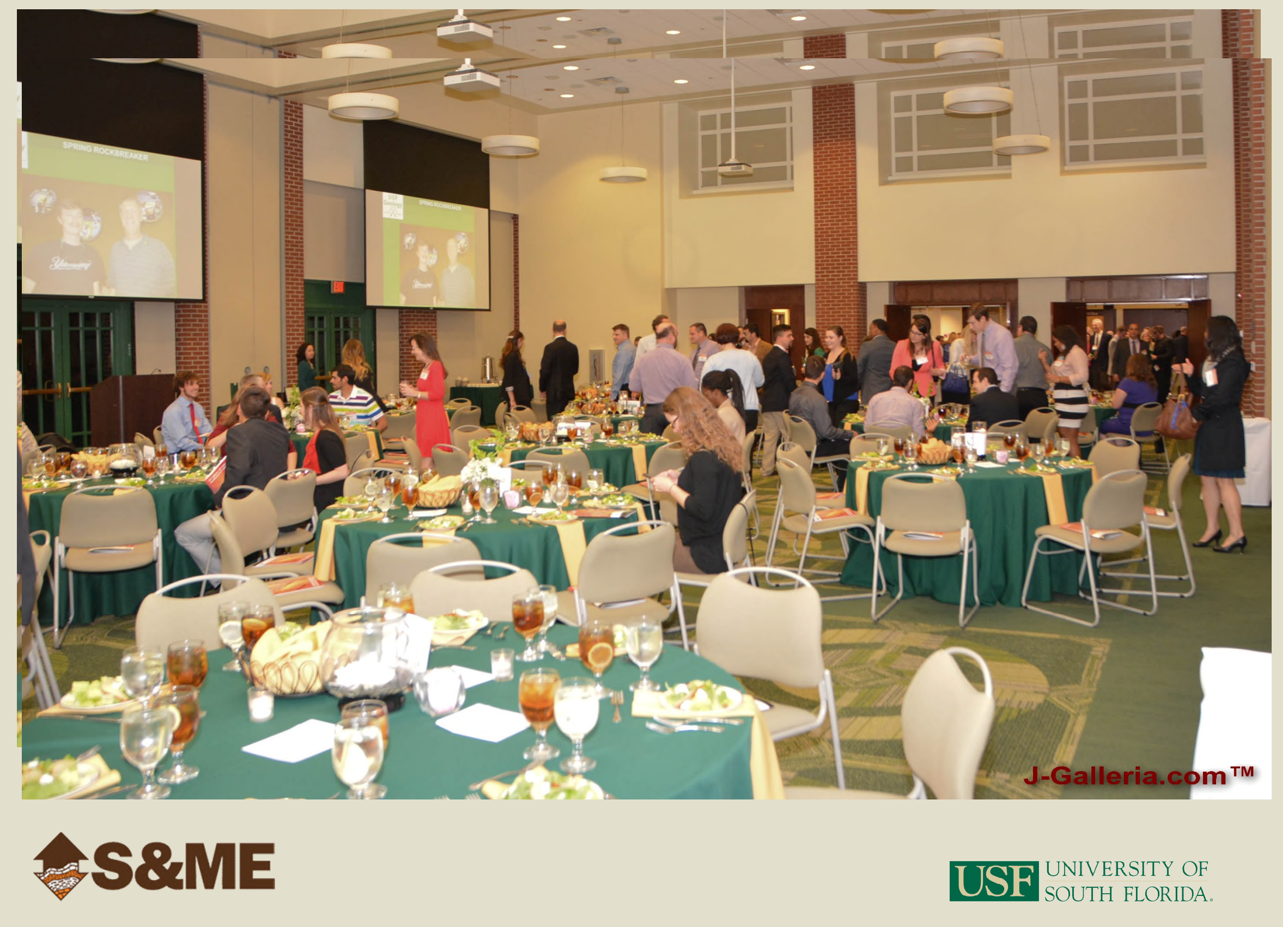




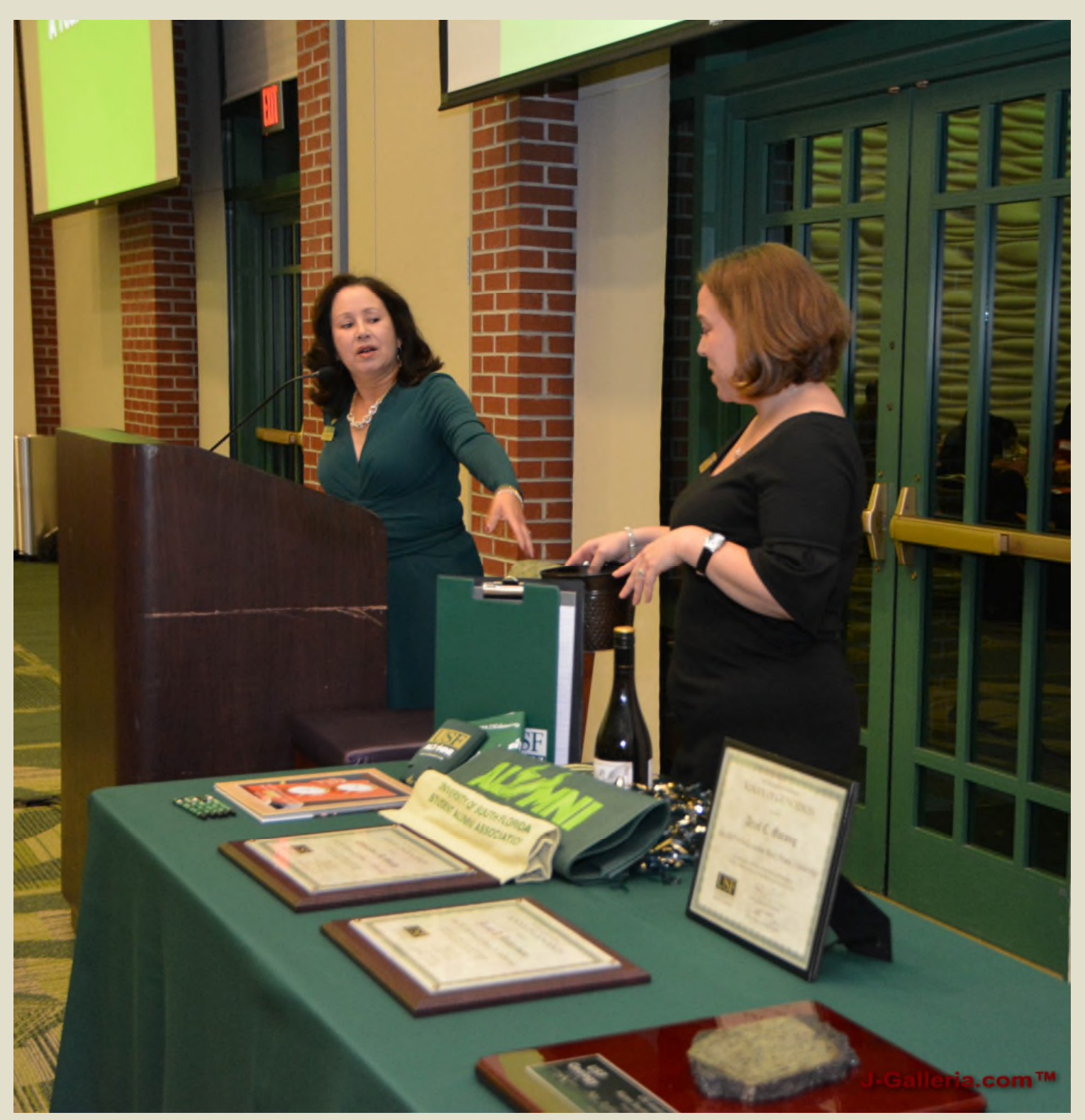

A-S\&ME

USF UNIVERSITY OF 


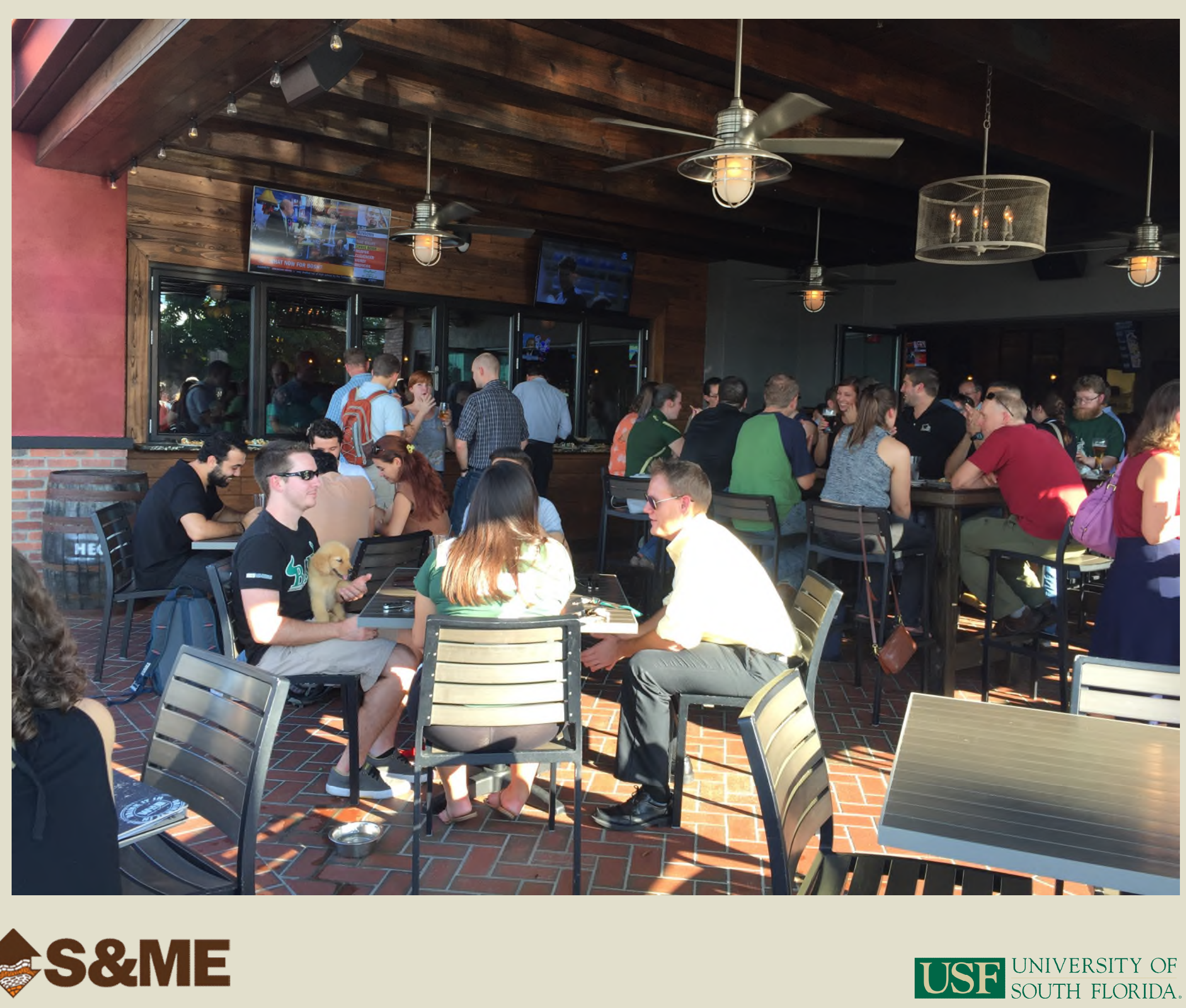




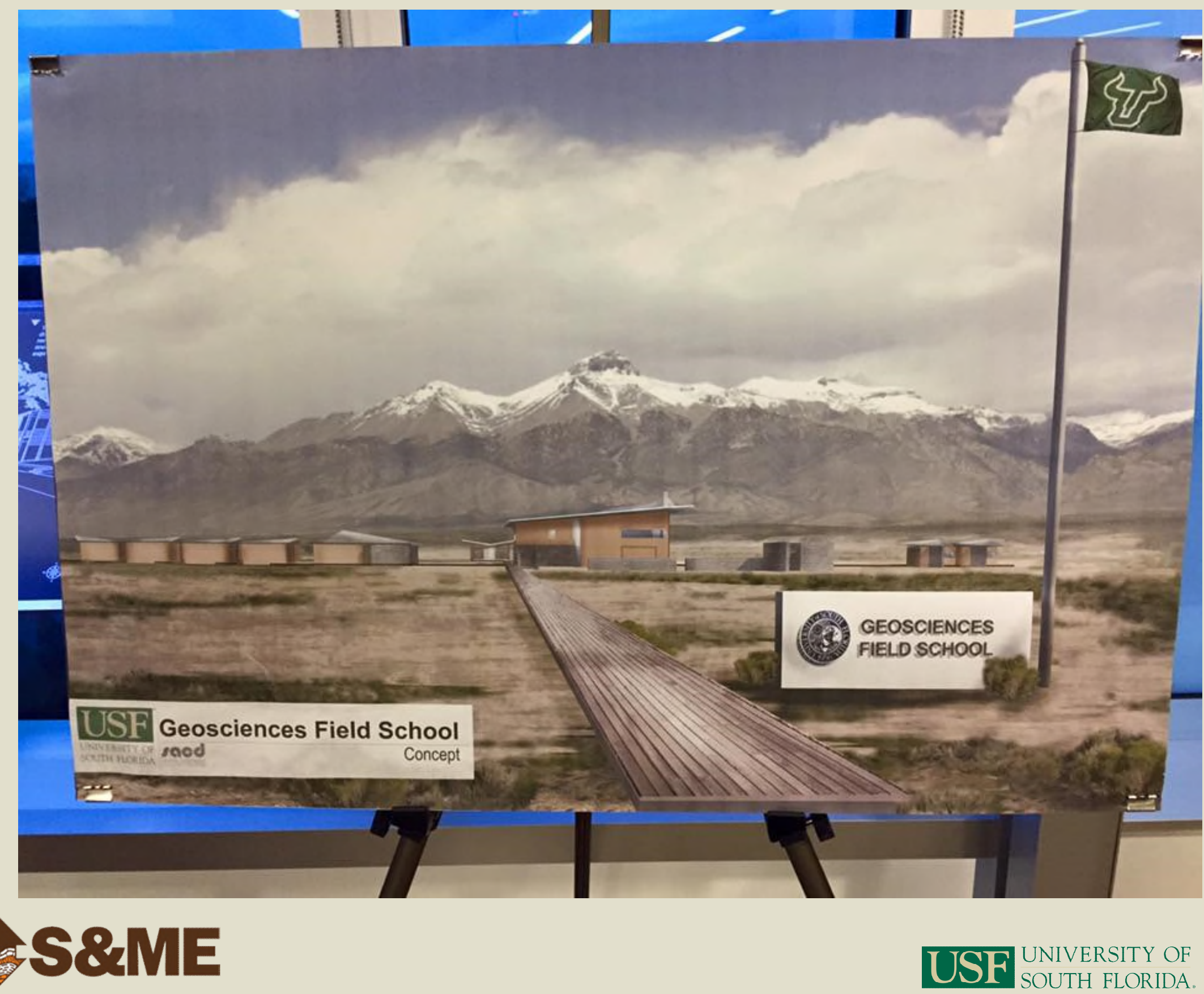




\section{CURRICULUM DEVELOPMENT AND COURSES}

- USF alumni and other professionals have helped to develop courses and also revise and improve the undergraduate curricula and the framework for Professional Science Masters Program $\left(\mathrm{PSM}^{*}\right)$.

- The PSM is a non-thesis option that is in the process of being revamped to provide 8 tracks for students to choose from:

- Hydrogeology

- Coastal Geology

- General Geology

- Wetlands/Hydrology
Environmental Geochemistry

Environmental Geophysics

Computational Geophysics

Geospatial Technology 


\section{COURSES}

\section{UNDERGRADUATE Preparing for a Career in Geoscience}

- 1-hour class, pass/fail

- Weekly visits from professionals talk about their jobs and careers

\author{
GRADUATE \\ Introduction to \\ Professional Geoscience
}

- 3-hour class

- Required for the PGSM

- Weekly topics that delve into the nuts and bolts of being a professional geologist 


\section{Introduction to Professional Geoscience}

- Be more aware of the professional geology environment surrounding them.

- Better understand the day-to-day tasks associated with a variety of geoscience careers.

- Includes a "networking" event.

- Emphasizes the importance of transferrable skills.

- Professional ethics is a constant, underlying theme. 


\section{CAPSTONES}

- Directed Research (3 hours)

- Comprehensive Exam

- Internship 


\section{INTERNSHIPS}

- Path toward receiving a Professional Science Masters Degree

- Local private companies and government (state and federal) agencies take on interns.

- There is a fairly high employment record following an internship.

- Fall and Spring Internship symposia 


\title{
QUESTIONS?
}

\section{Bruce Nocita}

\author{
bnocita@usf.edu
}

